[Article]

\title{
硅(111)衬底上直接接枝袻基的方法
}

\author{
张小宁 ${ }^{*}$ HOLLIMON Valerie BRODUS DaShan \\ (Department of Mathematics, Sciences and Technology, Paine College, Augusta 30901, Georgia, USA)
}

\begin{abstract}
摘要: 硅祄底是很有应用前景的表面。这是因为硅祄底在机械上和化学上的适应性能够抵御水环境和有机环 境带来的影响。除此之外, 优良的电学性质也是它们成为具有应用前景的表面的原因。目前有许多方法来进 行硅表面的颈基化, 很多情况下是将具有一SH末端的分子接枝到硅祄底上。但这些方法存在反应时间长的 问题。在这篇报导中, 我们发展了一种新的硅表面颈基化方法。这种方法可以实现将巯基直接接枝到硅片表 面。新方法需要对硅祄底进行氯化和颈基化反应, 所需的反应时间缩短。X射线光电子能谱(XPS)和接触角 测量被用于研究反应中每个步骤的表面表征。
\end{abstract}

关键词：硅(111)祄底；表面颈基化；X射线光电子能谱；接触角测量

中图分类号: 0647

\section{A Method for Attaching Thiol Groups Directly on a Silicon (111) Substrate}

\author{
ZHANG Xiao-Ning* HOLLIMON Valerie BRODUS DaShan \\ (Department of Mathematics, Sciences and Technology, Paine College, Augusta 30901, Georgia, USA)
}

\begin{abstract}
Silicon surfaces are promising interfaces because they are mechanically and chemically resilient, able to resist wear in aqueous and organic environments, and display good electrical properties. There are a number of methods that are used to thiolate a silicon surface, notably through the attachment of molecules that contain terminal $-\mathrm{SH}$ moieties. These methods usually suffer from long reaction times. In the present work, we developed an alternative method for thiolation of a silicon surface by introducing terminal thiol groups directly onto the silicon surface. The developed wet chemical process relies on chlorination and then surface thiolation and requires less time for grafting thiol groups on the silicon substrate. X-ray photoelectron spectroscopy (XPS) and contact angle measurement were employed for surface characterization after each step.
\end{abstract}

Key Words: Silicon (111) substrate; Surface thiolation; X-ray photoelectron spectroscopy; Contact angle measurement

\section{Introduction}

Silicon and silicon-based materials are integral parts of our daily life. For instance, silicone has found widespread applications in healthcare due to its unique material properties, including high flexibility, low biological activity, ease of fabrication, and chemical and thermal stability ${ }^{1}$. In addition, silicon is also the basic constituent for tubing, microfluidic system, catheters, drains, shunts, joint implants, silastic mammary prosthesis, and contact lenses ${ }^{2-4}$. Silicon-based materials, such as $\mathrm{Si}_{x} \mathrm{~N}_{4}$, having excellent fracture toughness and chemically inert, are often used as an insulator and chemical barrier in manufacturing integrated circuits. The surface modification of silicon and silicon-based materials with different functional groups has also been extensively studied as the functionalization of silicon and silicon-based materials has the potential to provide a controlled interface for various applications such as biosensors, photovoltaics, microfluidics, etc ${ }^{6-8}$.

Surface thiolation is an effective way to allow formation of surface functionalities of substrates, as thiol group can serve as

Received: April 18, 2016; Revised: May 18, 2016; Published online: May 18, 2016.

*Corresponding author. Email: XZhang@paine.edu; Tel: +1-706-821-8384.

The project was supported by the National Science Foundation, USA (HRD-1505197).

美国国家自然科学基金(HRD-1505197)资助项目

(c) Editorial office of Acta Physico-Chimica Sinica 
crosslinker for covalent binding of functional molecules', nanoparticles ${ }^{10}$, or biomaterials ${ }^{11}$ to the substrate. Silicon surface thiolation can be achieved through organic synthetic methods. However, these methods frequently suffered from disadvantage of long reaction time $\mathrm{i}^{12-15}$. For example, Zuilhof and colleagues ${ }^{16}$ have demonstrated the use of a photochemical approach for the attachment of thiol-terminated functional molecules onto Si surfaces. In their method, the diene-containing molecules were first attached to a hydrogen-terminated silicon surface via a wet chemical method. Then, thiolacetic acid was used to functionalize the alkeneterminated monolayers with a UV lamp (365 nm) under ambient conditions. Subsequently, the thioester groups were deprotected with sodium methoxide to expose terminal $-\mathrm{SH}$ moieties. This process suffers from long reaction time (about $18 \mathrm{~h}$ ). In order to shorten the reaction time, we developed a new route, which requires about $4 \mathrm{~h}$ for the whole steps, for a thiol-terminated silicon surface preparation.

\section{Materials and methods}

\subsection{Materials}

Anhydrous $N, N$-dimethylformamide (99.8\%) was purchased from Fisher Scientific (United States). Anhydrous benzene ( $\geq 98 \%$ ), anhydrous alcohol ( $\leq 0.005 \%$ water), sodium hydrosulfide hydrate (pure), tetrabutylammonium iodide (98\%), benzoyl peroxide ( $\geq 98 \%$ ), phosphorus chloride ( $\geq 98 \%$ ), sulfuric acid $(95 \%-98 \%)$, hydrogen peroxide (30\%, mass fraction), and ultraflat silicon (111) wafers (N-type) were purchased from Sigma-Aldrich (United States).

\subsection{Instrumentation}

X-ray photoelectron spectra (XPS) were collected on a Kratos Axis Ultra DLD X-ray Photoelectron Spectrometer (United Kingdom) under an ultrahigh-vacuum system, at a base pressure of $1.33 \times 10^{-7} \mathrm{~Pa}$, equipped with an $\mathrm{Al} K_{\alpha} \mathrm{X}$-ray source. Survey spectra were obtained at a $1 \mathrm{eV}$ resolution and high-resolution spectra were collected at $0.1 \mathrm{eV}$. All spectral analysis was performed with the Kratos analytical software package (Vision 2.2.10 Rev 4).

Contact angle measurements (static angles) were conducted at $25{ }^{\circ} \mathrm{C}$ with $18 \mathrm{M} \Omega \cdot \mathrm{cm}$ deionized (DI) water using a homemade experimental setup ${ }^{17}$. The droplet size used in contact angle measurements is $8 \mu \mathrm{L}$ so that there is no influence of gravity on contact angle values measurement ${ }^{18}$. Water contact angles were measured from four different positions on the surface. Deionized water was obtained from a Millipore Direct-Q 3 water purification system (United States).

\subsection{Surface preparation}

\subsubsection{Hydrogenation of silicon (111) surfaces}

Silicon wafers were cut into $1 \mathrm{~cm} \times 1 \mathrm{~cm}$ pieces. The wafer samples were cleaned by piranha solution ( 1 part of $\mathrm{H}_{2} \mathrm{SO}_{4}$ and 2 parts of $\mathrm{H}_{2} \mathrm{O}_{2}$ ) at $125^{\circ} \mathrm{C}$ for $15 \mathrm{~min}^{19,20}$. After rinsing the samples in deionized water and drying under a stream of $\mathrm{N}_{2}(\mathrm{~g})$, the oxidized silicon samples were etched in the $5: 1(V / V) \mathrm{NH}_{4} \mathrm{~F} / \mathrm{HF}(\mathrm{aq})$ solution for $1 \mathrm{~min}$ and then, without rinsing, were immersed into
$40 \% \mathrm{NH}_{4} \mathrm{~F}(\mathrm{aq})$ solution for $10 \mathrm{~min}^{21}$. The samples were subsequently removed from the $\mathrm{NH}_{4} \mathrm{~F}(\mathrm{aq})$, rinsed briefly with deionized water and dried under a stream of $\mathrm{N}_{2}(\mathrm{~g})$.

\subsubsection{Chlorination of hydrogen-terminated silicon (111) surfaces}

The chlorination of these freshly prepared $\mathrm{H}$-terminated $\mathrm{Si}$ surfaces was then performed using a wet chemistry method by immersing the $\mathrm{H}$-terminated $\mathrm{Si}$ sample into a $10 \mathrm{~mL}$ saturated solution of $\mathrm{PCl}_{5}\left(0.6-0.7 \mathrm{~mol} \cdot \mathrm{L}^{-1}\right)$ with benzoyl peroxide $(5 \mathrm{mg})$ as the radical initiator in anhydrous benzene at $80{ }^{\circ} \mathrm{C}$ for $1 \mathrm{~h}^{6,22}$. After reaction, the samples were thoroughly rinsed with copious amounts of benzene. The chlorinated substrates were then dried under a stream of $\mathrm{N}_{2}(\mathrm{~g})$. Scheme 1 describes the surface hydrogenation and chlorination process.

\subsubsection{Surface thiolation}

The chlorinated substrates will be placed in an anhydrous $\mathrm{N}, \mathrm{N}$ dimethylformamide (DMF) solution containing $500 \mathrm{mmol} \cdot \mathrm{L}^{-1}$ sodium hydrogen sulfide $(\mathrm{NaSH})$ and $100 \mathrm{mmol} \cdot \mathrm{L}^{-1}$ tetrabutylammonium iodide (TBAI) at $65^{\circ} \mathrm{C}$ for $2 \mathrm{~h}$ (Scheme 2$)^{23}$. The surfaces were thoroughly rinsed with anhydrous ethanol and dried under a stream of nitrogen gas after reaction.

\section{Results and discussion}

The hydrogen-terminated silicon surfaces were the starting point of our investigations in this work. The hydrogen atoms completely terminated silicon surface is relatively chemically unreactive in ambient air, thus, is good for the development of wet chemical functionalization reactions. Fig.1 demonstrates the highresolution spectra of the Si $2 p$ region for an $\mathrm{NH}_{4} \mathrm{~F}$ (aq) freshly etched silicon surface. The complete disappearance of the oxidized Si peak confirms full hydrogen coverage of the silicon surface.

Hydrogen-terminated silicon surface were also characterized with a home-made contact angle experimental set-up. The average water contact angle on a Piranha solution freshly cleaned silicon surface was found to be close to $0^{\circ}$ (Fig.1b). This low water contact angle reflects well with the hydrophilic, oxide-covered silicon surface left by the Piranha cleaning treatment. Strong hydrogen-bonding interaction between $\mathrm{SiO}_{x}$ and water allows the water droplet to spread on the silicon surface. After the hydrogen termination process on the silicon surface, the water contact angles showed a steep increase and reached a level of $83.4^{\circ} \pm 0.9^{\circ}$ (Fig.1c). The large contact angle is indicative of the hydrophobic nature of hydrogen-terminated silicon surface.
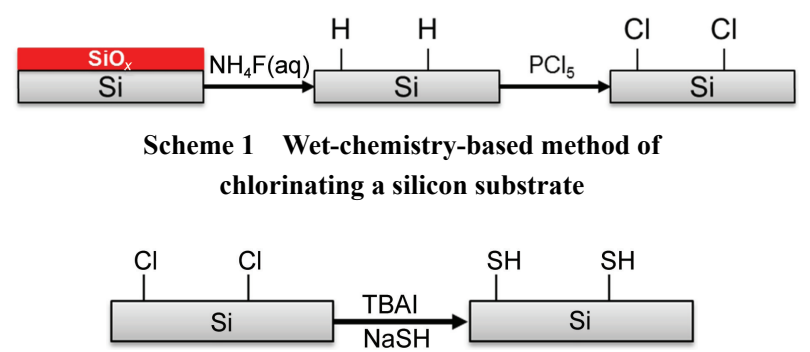

Scheme 2 Preparation of thiol groups terminated silicon surface 


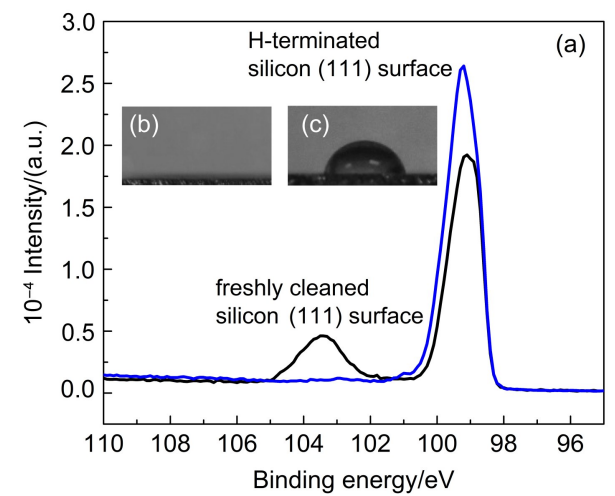

Fig.1 (a) High-resolution XPS spectra of the Si $2 p$ region of a Si (111) surface before (black line) and after (blue line) $\mathrm{NH}_{4} \mathrm{~F}(\mathrm{aq})$ etching

Inset figures present contact angle of water hemisphere on Piranha solution cleaned silicon surface (b) and hydrogen terminated silicon surface (c). color online

We chlorinated the hydrogen-terminated surfaces using a modified procedure first described by Lewis and coworkers ${ }^{6}$ : the surfaces were incubated in benzene containing $\mathrm{PCl}_{5}$ and benzoyl peroxide. Upon chlorination, the XPS survey spectra (Fig.2) showed peaks at 271 binding electron volts, $\mathrm{eV},(\mathrm{Cl} 2 s)$ and 200 $\mathrm{eV}(\mathrm{Cl} 2 p)$, indicating that this procedure yielded $\mathrm{Cl}$ on the surface. Trace amounts of $\mathrm{C}$ were observed at $285 \mathrm{eV}$ which arise from adventitious carbonaceous material ${ }^{6}$. However, a large $\mathrm{O} 1 \mathrm{~s}$ peak was observed at a binding energy of $532 \mathrm{eV}$. The magnitude of this oxygen peak is higher than observed in Lewis and colleagues' results ${ }^{24}$. The experiment performed by Lewis' group using a customized experimental set up in which $\mathrm{N}_{2}(\mathrm{~g})$-purged glovebox, where the surface modification reactions were conducted, directly connected with XPS ultrahigh vacuum system via a quick-entry load lock ${ }^{24}$. This customized experimental setup effectively prevents the prepared samples from being exposed to ambient air and limits the oxygen content on the chlorinatated $\mathrm{Si}$ surface as $\mathrm{Si}-\mathrm{Cl}$ surface is susceptible to hydrolysis ${ }^{25}$.

The chlorinated substrates were consequently placed in an anhydrous DMF solution containing sodium hydrogen sulfide $(\mathrm{NaSH})$ and TBAI at $65^{\circ} \mathrm{C}$ for $2 \mathrm{~h}$. Sodium hydrogen sulfide $(\mathrm{NaSH})$ was employed as the thiolating reagent for two reasons: (i) under similar reaction conditions, more sulfur was incorporated

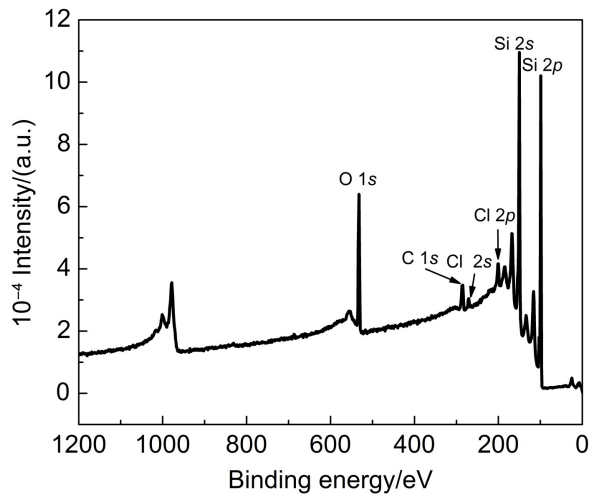

Fig.2 XPS survey spectra of chlorinated Si (111) surface on the surface with $\mathrm{NaSH}$ than with potassium thioacetate ${ }^{26}$ or thiourea $^{21}$; (ii) thioacetate and thiourea require a deprotection step after they are attached to the surface, where NaSH does not. In this step, TBAI was used to drive reaction faster. This is because the iodide is a strong nucleophile and can substitute for the chloride. Since iodide is a better leaving group than chloride, it can be attacked by the $-\mathrm{SH}$ anion group more easily.

As compared to the Cl-terminated surface, the survey spectrum of the thiol-terminated surface (Fig.3) displayed two additional peaks, at 234.0 and $170.0 \mathrm{eV}$, respectively, corresponding to signals arising from $\mathrm{S} 2 s$ and $\mathrm{S} 2 p$ photoelectrons. No $\mathrm{Cl}$ peaks were observed. None of the peaks changed in amplitude or position after the sonication of the Si surfaces in anhydrous DMF. The contact angle of water on thiol-terminated silicon surface was measured to $22.8^{\circ} \pm 0.7^{\circ}$

Peak fitting of the S $2 s$ envelope was used to determine the existence of thiol on the surface. The $\mathrm{S} 2 s$ peak was used in this analysis instead of using S $2 p$ peak is because it can avoid any possible overlap of the S $2 p(160-169 \mathrm{eV})$ region with the Si $2 s$ $(155-165 \mathrm{eV})$ signal from the substrate ${ }^{27}$, and also because S $2 s$ appears as a simpler, single peak, and not a spin-orbit doublet ${ }^{15}$. As shown in Fig.4, the S $2 s$ region could be deconvoluted into seven components. According to the prior literature report ${ }^{15}$, the

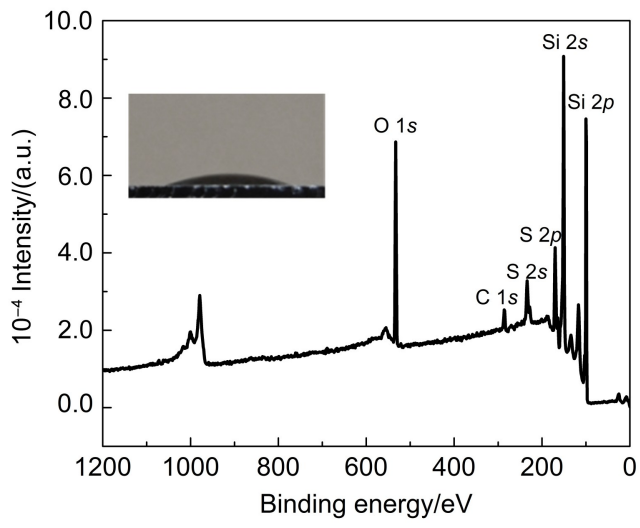

Fig.3 XPS survey spectra of SH-terminated Si (111) surface Inset figure presents contact angle of water hemisphere on SH-terminated $\mathrm{Si}$ (111) surface.

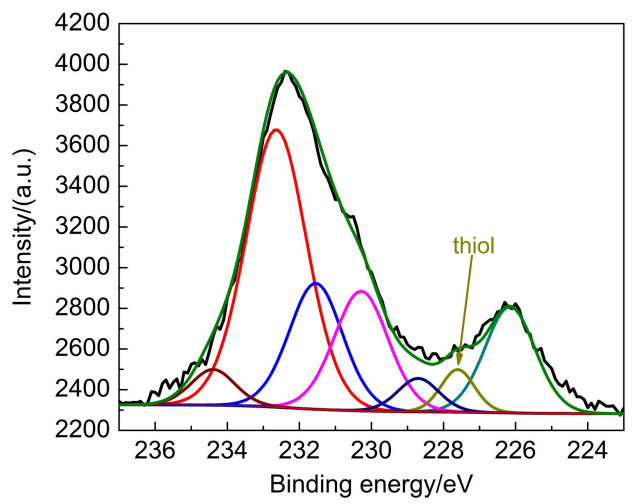

Fig.4 High-resolution XPS spectra of $S 2 s$ region of a Si (111) surface 
peak at $(227.6 \pm 0.1) \mathrm{eV}$ is attributed to thiol groups. It should be noticed that because of the rapid oxidation of thiol groups, the as prepared thiolated silicon surfaces have much more component of thiols demonstrated in Fig.4.

The existence of terminal thiol groups was approved by attaching the thiol terminated molecules through the formation of a disulfide bond. Thiolated silicon surfaces were submerged in 100 $\mathrm{mmol} \cdot \mathrm{L}^{-1} 1 H, 1 H, 2 H, 2 H$-perfluorodecanethiol (PFDT) anhydrous ethanol solution immediately after they are prepared for $2 \mathrm{~h}$. Through the formation of the disulfide bond, PFDT should be able to immobilize on the substrate as shown in Scheme 3. Samples were then rinsed with anhydrous ethanol, sonicated in anhydrous ethanol for $5 \mathrm{~min}$, rinsed with anhydrous ethanol again, and dried with a stream of nitrogen.

The contact angle of water on the PFDT terminated silicon surface was measured to $66.2^{\circ} \pm 1.1^{\circ}$ (Fig.5). The peak at $689 \mathrm{eV}$ in XPS survey spectra (Fig.5) was assigned as F $1 s$. Both contact angle measurement and XPS analysis indicate that the PFDT was successfully grafted to the SH-terminated Si substrate. Besides, the carbon intensity in the XPS survey scan increased when the chemistry was performed with PFDT.

As a control experiment, freshly prepared thiolated silicon surfaces were submerged in $100 \mathrm{mmol} \cdot \mathrm{L}^{-1} 1 H, 1 H, 2 H, 2 H$-perfluoro-1-decanol anhydrous ethanol solution for $2 \mathrm{~h}$. The lack of F peak in XPS survey spectra (Fig.6) confirms that $1 H, 1 H, 2 H, 2 H$ -

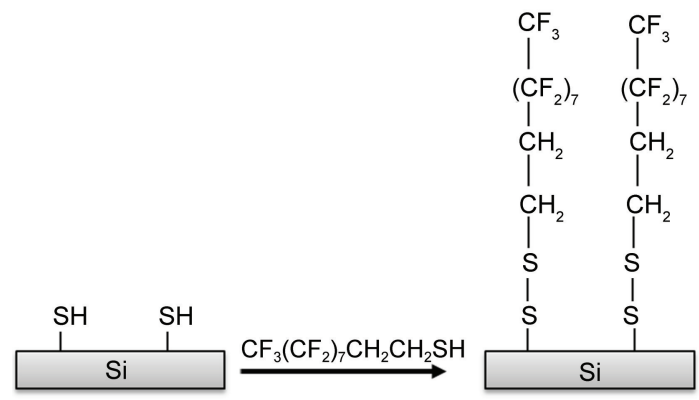

Scheme $31 H, 1 H, 2 H, 2 H$-Perfluorodecanethiol molecules crosslink thiol groups on the silicon substrate by disulfide bonds

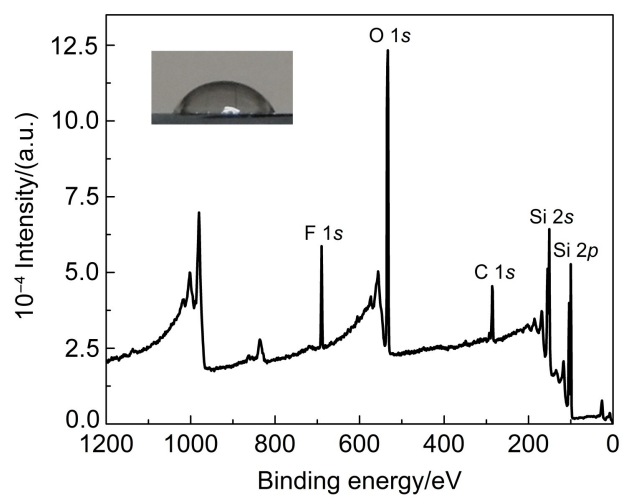

Fig.5 XPS survey spectra of $\mathrm{SHCH}_{2} \mathrm{CH}_{2}\left(\mathrm{CF}_{2}\right)_{7} \mathrm{CF}_{3}$ terminated Si (111) surface

Inset figure presents contact angle of water hemisphere on $\mathrm{SHCH}_{2} \mathrm{CH}_{2}\left(\mathrm{CF}_{2}\right)_{7} \mathrm{CF}_{3}$ terminated $\mathrm{Si}$ (111) surface.

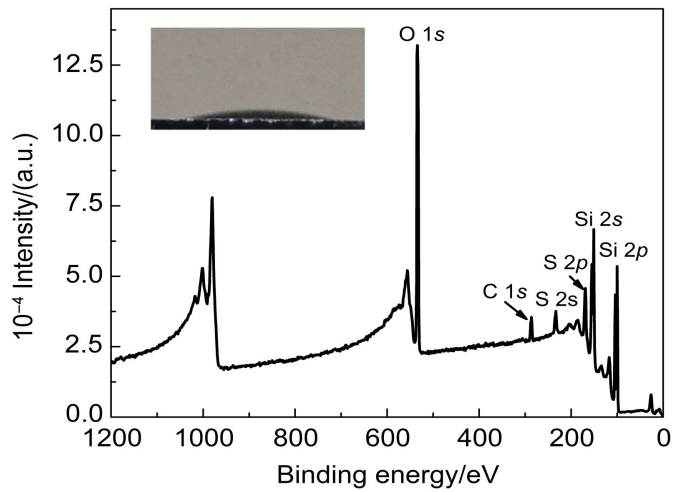

Fig.6 XPS survey spectra of SH-terminated Si (111) surface after submerging in $100 \mathrm{mmol} \cdot \mathrm{L}^{-1} 1 \mathrm{H}, 1 \mathrm{H}, 2 \mathrm{H}, 2 \mathrm{H}$-perfluoro-1-decanol anhydrous ethanol solution for $\mathbf{2} \mathbf{h}$

Inset figure presents contact angle of water hemisphere on such surface.

perfluoro-1-decanol did not graft on the thiol terminated silicon substrates. The result is reasonable as thiol groups cannot form covalent bonds with hydroxyl groups, which is the terminal group in molecule $1 \mathrm{H}, 1 \mathrm{H}, 2 \mathrm{H}, 2 \mathrm{H}$-perfluoro-1-decanol. Contact angle measurements showed that the contact angle of the water droplet on the prepared surface was $21.3^{\circ} \pm 1.1^{\circ}$, which further confirmed the absence of $1 H, 1 H, 2 H, 2 H$-perfluoro-1-decanol on the substrate.

\section{Conclusions}

A wet chemical process was developed for silicon surface thiolation in this study. The attachment of PFDT was used to approve the successful grafting of thiol groups on silicon surface. XPS and contact angle measurement were employed for the surface characterization. Because thiol group can serve as crosslinker for the covalent binding of functional molecules, the approach developed by this study is potentially important in fabricating silicon and silicon-based materials with surface functionalities for various applications.

\section{References}

(1) Yoda, R. J. Biomater Sci. Polym. Ed. 1998, 9, 561. doi: 10.1163/ $156856298 \mathrm{X} 00046$

(2) Yeh, S. B.; Chen, C. S.; Chen, W. Y.; Huang, C. J. Langmuir 2014, 30, 11386. doi: 10.1021/1a502486e

(3) Stamm, W. E. Am. J. Med. 1991, 91, S65. doi: 10.1016/00029343(91)90345-X

(4) Warren, J. W. Int. J. Antimicrob. Agents 2001, 17, 299. doi: 10.1016/S0924-8579(00)00359-9

(5) Bermudez, V. M.; Perkins, F. K. Appl. Surf. Sci. 2004, 235, 406. doi: 10.1016/j.apsusc.2004.02.065

(6) Bansal, A.; Li, X.; Lauermann, I.; Lewis, N. S.; Yi, S. I.; Weinberg, W. J. Am. Chem. Soc. 1996, 118, 7225. doi: 10.1021/ ja960348n

(7) Li, X.; He, Y.; Swihart, M. T. Langmuir 2004, 20, 4720. doi: $10.1021 / 1 \mathrm{a} 036219 \mathrm{j}$

(8) Gooding, J. J.; Ciampi, S. Chem. Soc. Rev. 2011, 40, 2704. 
doi: $10.1039 / \mathrm{C} 0 \mathrm{CS} 00139 \mathrm{~B}$

(9) Goldmann, A. S.; Walther, A.; Nebhani, L.; Joso, R.; Ernst, D.; Loos, K.; Barner-Kowollik, C.; Barner, L.; Müller, A. H. Macromolecules 2009, 42, 3707. doi: 10.1021/ma900332d

(10) Sperling, R. A.; Parak, W. J. Phil. Trans. R. Soc. A 2010, 368 , 1333. doi: 10.1098/rsta.2009.0273

(11) Bhatia, S. K.; Shriver-Lake, L. C.; Prior, K. J.; Georger, J. H.; Calvert, J. M.; Bredehorst, R.; Ligler, F. S. Anal. Biochem. 1989, 178, 408. doi: 10.1016/0003-2697(89)90662-3

(12) He, H.; Averick, S.; Roth, E.; Luebke, D.; Nulwala, H.; Matyjaszewski, K. Polymer 2014, 55, 3330. doi: 10.1016/j. polymer.2014.01.045

(13) Haddada, M. B.; Blanchard, J.; Casale, S.; Krafft, J. M.; Vallée, A.; Méthivier, C.; Boujday, S. Gold Bull 2013, 46, 335. doi: 10.1007/s13404-013-0120-y

(14) Hensarling, R. M.; Hoff, E. A.; LeBlanc, A. P.; Guo, W.; Rahane, S. B.; Patton, D. L. J. Polym. Sci. Part A: Polym. Chem. 2013, 51, 1079. doi: 10.1002/pola.26468

(15) Madaan, N.; Romriell, N.; Tuscano, J.; Schlaad, H.; Linford, M. R. J. Colloid Interface Sci. 2015, 459, 199. doi: 10.1016/j. jcis.2015.08.017

(16) Bhairamadgi, N. S.; Gangarapu, S.; Caipa Campos, M. A.; Paulusse, J. M. J.; van Rijn, C. J. M.; Zuilhof, H. Langmuir 2013, 29, 4535. doi: 10.1021/1a400007y

(17) Lamour, G.; Hamraoui, A.; Buvailo, A.; Xing, Y.; Keuleyan, S.;
Prakash, V.; Eftekhari-Bafrooei, A.; Borguet, E. J. Chem. Educ. 2010, 87,1403 . doi: $10.1021 /$ ed100468u

(18) Drelich, J.; Miller, J. D.; Hupka, J. J. Colloid Interface Sci. 1993, 155, 379. doi: 10.1006/jcis. 1993.1050

(19) Zhang, X.; Cai, Y. Beilstein J. Nanotechnol. 2012, 3, 33. doi: 10.3762/bjnano.3.4

(20) Trajkovic, S.; Zhang, X.; Daunert, S.; Cai, Y. Langmuir 2011, 27, 10793. doi: 10.1021/la2016885

(21) Bansal, A.; Li, X.; Yi, S. I.; Weinberg, W.; Lewis, N. S. J. Phys. Chem. B 2001, 105, 10266. doi: 10.1021/jp010284p

(22) Nemanick, E. J.; Hurley, P. T.; Brunschwig, B. S.; Lewis, N. S. J. Phys. Chem. B 2006, 110, 14800. doi: 10.1021/jp057070i

(23) Wang, C.; Sun, L. L.; Hu, B. L.; Zhang, X. G.; Chen, F., Tetrahedron 2014, 70, 7969. doi: 10.1016/j.tet.2014.08.049

(24) Webb, L. J.; Lewis, N. S. J. Phys. Chem. B 2003, 107, 5404 doi: $10.1021 / \mathrm{jp} 0222752$

(25) Xu, F. J.; Cai, Q. J.; Kang, E. T.; Neoh, K. G. Langmuir 2005, 21, 3221. doi: 10.1021/la0473714

(26) Kobayashi, S.; Hachiya, I.; Suzuki, S.; Moriwaki, M. Tetrahedron Lett. 1996, 37, 2809. doi: 10.1016/0040-4039(96) 00435-2

(27) Bukhtiyarova, G.; Bukhtiyarov, V.; Sakaeva, N.; Kaichev, V.; Zolotovskii, B. J. Mol. Catal. A: Chem. 2000, 158, 251. doi: 10.1016/S1381-1169(00)00085-6 